\title{
Health Professionals' Readiness And Its Associated Factors To Implement Telemedicine System At Private Hospitals In Amhara Region, Ethiopia 2021
}

Sisay Maru Wubante ( $\sim$ sisay419@gmail.com )

University of Gondar

Araya Mesfin Nigatu

University of Gondar

Adamu Takele Jemere

University of Gondar

\section{Research Article}

Keywords: Telemedicine, Readiness, Health Professionals, factors, Ethiopia

Posted Date: March 7th, 2022

DOI: https://doi.org/10.21203/rs.3.rs-1365080/v1

License: (c) (i) This work is licensed under a Creative Commons Attribution 4.0 International License.

Read Full License 


\section{Abstract}

Introduction: in resource-limited settings incorporating the Telemedicine system into the healthcare system enhances exchanging valid health information for practicing evidence-based medicine for the diagnosis, treatment, and prevention of diseases. The successful implementation of a telemedicine system in health care inquires a study of numerous technical, organizational, infrastructure, and human elements.

Objective: This study aimed to assess health professionals' readiness and its associated factors to implement a Telemedicine system at private hospitals in Amhara Region, Ethiopia 2021.

Method: An institution-based cross-sectional study was conducted among 423 health professionals from March 3 to April 72021 at private hospitals in Amhara Region. A self-administered questionnaire was employed to collect the data. The data were analyzed by SPSS version 20 software. Descriptive statistics,bi-variable and multi-variable logistic regression analyses were performed. An adjusted odds ratio (AOR) with $95 \% \mathrm{Cl}$ was used to determine the s association between the independent and the outcome variable.

Result: About Two-third $(268 ; 65.4 \%)$ of health professionals were ready to Telemedicine system.Knowledge (AOR=2.5;95\% Cl: [1.4, 4.6]), Attitude (AOR=3.2;95\% Cl: [(1.6,6.2]), computer literacy $(A O R=2.2 ; 95 \% \mathrm{Cl}:[1.3,3.9])$, computer training (AOR=2.1;95\% Cl: $[1.1,4.1])$, Computer skill (AOR=1.9;95\% $\mathrm{Cl}:[1.1,3.4])$,computer access at office (AOR $=2.1 ; 95 \% \mathrm{Cl}:[1.1,3.7]$,Internet access at office (AOR=2.8;95\% Cl: [1.6,5.1]),Own personal computer(AOR=3.0;95\% Cl: [1.5,5.9])and work experience(AOR=3.1;95\%Cl: $[1.4,6.7])$ were significantly associated withTelemedicine readiness .

Conclusion and Recommendation: In general the overall readiness of health professionals for the Telemedicine system is moderate. Inclusive packages of capacity building are fundamental to increasing the level of, knowledge, attitude, and training among health professionals.

\section{Introduction}

Information and Communication Technology (ICT) is being used to improve health care access, productivity, and efficiency in both developed and developing countries $\left({ }^{1)}\right.$. Telemedicine is one of the innovative systems that use ICT and telecommunication infrastructures to support and enable longdistance patient care, the management of patient data, and the provision of patient and professional communication platforms ${ }^{(2)}$.

Incorporating the telemedicine system into the healthcare system is not all about exchanging valid health information for practicing evidence-based medicine for the diagnosis, treatment, and prevention of diseases but It is about saving the time of both the doctor and the patients for seeing their consultants ( 3 , 4). 
Despite many benefits are offered by the telemedicine system to the healthcare sector, the adoption and utilization of telemedicine in low resource-limited countries $\operatorname{are~limited~}^{(5)}$.

Various healthcare facilities throughout the world have introduced telemedicine systems to enhance health information exchange between health professionals to make evidence-based decisions about a particular patient's health condition, but only a few have been successful ${ }^{(6)}$.

The percentages of adoption failures to obtain the potential benefits of implementation are alarmingly high. More than $75 \%$ of Telemedicine system projects fail to meet their targets globally ${ }^{(7)}$. However, there is a difference between countries. More than $76 \%$ of healthcare institutions in the USA have a fully functioning telemedicine system ${ }^{(8)}$. More than $75 \%$ in Norway and in developing countries $10 \%$ of their health care institutions have successfully implemented a Telemedicine system ${ }^{(7,9)}$.

A study conducted in Uganda Assessment of health provider readiness for telemedicine services of healthcare organizations found that overall readiness for the Telemedicine system was $64.7 \%(10)$.

A study conducted in Mauritius also showed the overall readiness of health professionals on Telemedicine system implementation was $64.5 \%{ }^{(11)}$.

Like other countries, the Ethiopian Ministry of Health has recognized the importance of ICT for accessibility, quality improvement in healthcare provision for the population.

From 2004 up to 2006, the Ethiopian Ministry of Health adopted a pilot telemedicine system at selected hospitals and planned to scale it up to all hospitals, but the implementation status of each hospital was $25 \%(12)$.

Various reasons are given for low Telemedicine system adoption, such as resistance, to change, lack of pre-implementation preparations, lacked internet connectivity, digital literacy, training, lack of organizational readiness, telecommunication infrastructures, ICT infrastructures unavailability of technology, funding, and lack of technical and computer skills of personnel ${ }^{(13-16)}$.

The successful implementation of a telemedicine system in health care inquires a study of numerous technical, organizational, infrastructure, and human elements $\left({ }^{17)}\right.$. Adoption of Telemedicine is a full-cycle process that is more than just a technological one; it needs several behavioral changes in the workplace for health workers. Before launching the Telemedicine system for hospitals, prerequisites must be addressed $\left({ }^{18)}\right.$. A readiness assessment is a comprehensive measure to identify potential reasons for failure in Telemedicine innovation to provide pertinent information on existing conditions and the preparedness of healthcare organizations to change.

Due to this, identifying health professionals' readiness and factors associated to use telemedicine was paramount for prioritizing intervention to promote telemedicine system use. With this background, fostering the benefit of telemedicine platforms, policy and interventions are crucial to increasing 
healthcare access for underserved communities and quality of care and sharing of valid health information for evidence-based decision making between health professionals. However, the implementation of a telemedicine system is very important, as per the investigator's search, there is a limited study about readiness to use a telemedicine system among health professionals in the Ethiopian context.

Therefore, this study assessed health professionals' readiness to use the telemedicine system and its associated factors among private hospitals in the Amhara region, Ethiopia.

\section{Method And Materials}

An institution-based cross-sectional quantitative approach was conducted among health professionals working at private hospitals in the Amhara Region from March 3to April 7, 2021. The study was conducted at private hospitals in the Amhara Region Ethiopia.

\section{Study Participants, Sample Size, and Sampling Procedure}

The study populations were health professionals working at private hospitals found in the Amhara Region, Ethiopia, and the sample size was calculated by using the single population proportion formula by considering $50 \%$ because there was no prior study conducted and considering a $10 \%$ non-response rate. Finally, a minimum sample size of 423 was obtained. All health professionals who were working at private Hospitals in the Amhara Region were considered as the source of population. All Health professionals who have less than six months of working experience in clinical practices were excluded from the study.

Study participants were selected from private hospitals found in North-West, Ethiopia. Among the private hospitals, study participants were selected using population proportion allocation for each hospital. The number of health care providers found by calculating population proportion allocation were selected using simple random sampling from the private hospitals, North-West Ethiopia

\section{Data Collection Tool and quality assurance}

Data were collected using a pretested and structured self-administered questionnaire. Sociodemographic, individual, technical, and organizational access to basic technologies variables were included in the questionnaire. It includes the Likert scale, yes or no questions. The questionnaire was first prepared in English and translated into Amharic for semantic consistency. Three-degree holder health professionals who have smart communication with others was supervisors and eight health information technician professionals participated in data collection. To control the quality of data, two days of training were given for data collectors and supervisors on the objective of the study, data collection procedures, data collection tools, respondents approach, data confidentiality, and respondent's right before the data collection date. Before the actual data collection, pretesting of the questionnaire was conducted about $10 \%$ of the study participants 


\section{Data management and statistical Analysis}

The data entry and analysis were done by using Epi info 7.2 version and SPSS version 20 respectively. Descriptive statistics on frequency and percentage were computed and have been presented in the form of texts, tables, and figures to describe the study population. We used binary logistic regression to analyze the association of independent variables on the outcome variables. The outcome variable was assigned as "No=0" (not ready), "Yes=1" (ready). Variables having statistically significant association with the outcome variable $(p<0.2)$, in the bi-variable analysis, were included in multivariable logistic regression analysis for controlling the effect of the confounder. In multivariable logistic regression model analysis, model fitness was checked by the Hosmer-Lemeshow test. Variables significant association was determined based on adjusted odd ration (AOR), with $95 \% \mathrm{Cl}$ and variables with $(p<0.05)$ were considered as determinant factors for health professional readiness towards the implementation of Telemedicine.

Health professionals' readiness: In this study health professionals' readiness was measured by a set of $15 q u e s t i o n s$ and participants who scored median and above were considered as ready, and participants who scored below the median were considered as not ready(19).

\section{Ethical Consideration}

Ethical clearance was obtained from the Institutional Review Board (IRB) of the University of Gondar College of medicine and health sciences, institute of public health with the reference number(RfNo/IPH/1493/2013). Informed written consent was obtained from the study participant after describing the objective of the study, they were also informed about the benefits of the study.

\section{Result}

\section{Socio-demographic characteristics of study participants}

In this study, a total of 423 health professionals from all private hospitals were approached, out of them, 410 were responded with a response rate of $96.9 \%$. More than half $226(55.1 \%)$ of the study participants were males. The majority (44.6\%) of the respondents were within the age group 25-29 years(Table 1 ).

\section{Technical factors for Telemedicine readiness}

From the total study participants, More than half $240(58.5 \%)$ of health professionals were computerliterate. About $245(59.8 \%)$ of study participants were had computer skills.

\section{The organizational factors for Telemedicine readiness}

About 245 (59.8\%) of study participants have had computer access at their office. Regarding, internet access at the office nearly two-thirds of $251(61.2 \%)$ of the health professionals had internet access at their office (Table 2). 
In this study, more than two-thirds 281 (68.5\%) of the study participants had good knowledge. Similarly, half $217(52.9 \%)$ of the study participants had a favorable attitude toward Telemedicine(Figure1).

\section{Health professional readiness to implement Telemedicine system}

From a total of study participants, 244(59.5\%) and 222(54.1\%) of study participants have had core and engagement readiness respectively. The result of this study indicated that two-thirds of $268(65.4 \%)$ with $95 \% \mathrm{Cl}:(60.1-69.8)$ of study participants were ready for the implementation of Telemedicine with moderate readiness(Figure 2 ).

\section{Factors Associated with health professionals readiness for the Telemedicine system.}

As shown in(Table3 ) multivariable logistic regression variables like Knowledge, Attitude, own personal computer, internet access at the office, Computer skill, computer literacy, computer training, Work experiences, and computer access at the office were associated with Telemedicine readiness.

Study participants who had good knowledge of Telemedicine were 2.5 times (AOR $=2.5 ; 95 \% \mathrm{Cl}$ : $[1.4,4.6])$ more likely ready for the Telemedicine system as compared with those study participants with poor knowledge.

Respondents who had a favorable attitude towards Telemedicine were 3.2 times (AOR $=3.2 ; 95 \% \mathrm{Cl}$ : [1.6, 6.2]) more likely ready for the Telemedicine system than those who have an unfavorable attitude.

Health professionals who had their personal computer were about 3.0 times (AOR $=3.0 ; 95 \% \mathrm{Cl}$ : $[1.5,5.9]$ ) more likely ready to use a Telemedicine relative to those study participants who had no personal computer.

Study participants with adequate computer skills were 1.9 times (AOR $=1.9 ; 95 \% \mathrm{Cl}$ : $[1.1,3.4]$ ) more likely ready for the implementation of Telemedicine than those with inadequate computer skills.

Health professionals having adequate computer literacy were 2.2 times $(\mathrm{AOR}=2.2 ; 95 \% \mathrm{Cl}:[1.3,3.9])$ more likely ready to implement Telemedicine than their counterparts. respondents who had taken formal training were about 2.1 times $(\mathrm{AOR}=2.1 ; 95 \% \mathrm{Cl}$ : $[1.1,4.1])$ more likely ready to implement Telemedicine than those who do not take it.

Those Study participants who had adequate internet access at the office were 2.8 times $(A O R=2.8 ; 95 \% \mathrm{Cl}$ : $[1.6,5.1])$ more likely ready towards the implementation of Telemedicine than those health professionals who had limited internet access.

\section{Discussion}

In this study, the readiness of health professionals for Telemedicine the system at private hospitals found in the Amhara Region was assessed. The overall readiness of health professionals for a Telemedicine system was $65.4 \%$ (with $59.5 \%$ core readiness and $54.1 \%$ engagement readiness). Health professionals' 
readiness for the telemedicine system in this study was in line with a study done in Uganda ${ }^{(20)}$. Similarly comparable with a study done in Mauritius on telemedicine readiness assessment among health care providers also reported consistent findings $(64.5 \%)$ of participants were ready ${ }^{(21)}$. However, this finding was slightly higher than a study done in Uganda(22). This discrepancy might be study period, study subjects, sample size study settings, The other reason could be the day-to-day exposure of health professionals to the global digital ecosystem.

In this study health professionals who had good knowledge of Telemedicine, the system was about 2.5 times more likely to be ready for a Telemedicine system as compared to health professionals with poor knowledge. This finding is consistent with the previous study conducted in Mauritius on health professionals' assessment of e-health readiness concluded that health professionals who had good knowledge of the telemedicine system were more likely ready for the telemedicine system than their counterparts ${ }^{(21)}$.

This study is also in line with the previous study done in Uganda on health care providers' readiness towards Telemedicine which reported that health professionals who had good knowledge of telemedicine were more likely ready as compared with health professionals with poor knowledge ${ }^{(20)}$. Moreover, consistent with a study conducted in Iran on awareness, attitude, and readiness towards Telemedicine on clinical staff argues that health professionals who had good knowledge of telemedicine are more likely ready as compared with their counterparts ${ }^{(23)}$.

This might be due to, health professionals with their prior knowledge may have helped their motivations to use the Telemedicine system. the speculation is per evidence suggested by another study done $e^{(24)}$, which confirmed that having a concept about Telemedicine improves ready for telemedicine system.

Health professionals who had a favorable attitude towards the telemedicine system were 3.2 more likely ready for the telemedicine system than their counterparts. This finding consistent with a study done in Uganda on core and technological readiness to integrate Telemedicine confirmed that health professionals who had a favorable attitude toward the telemedicine system were more likely ready for the telemedicine system than their counterparts ${ }^{(20)}$. Additionally, this study is also in line with a study done in Iran on awareness, attitude, and readiness of health professionals confirmed that the favorable attitude of health professionals toward telemedicine significantly ${ }^{(23)}$. Further, another study highlights that health professionals with a favorable attitude toward telemedicine were more likely ready for the telemedicine system $^{(25)}$.

This may be having a good view of Telemedicine can influence health workers' readiness to implement the Telemedicine system in their routine activities.

Study participants who had private personal computers were 3.0 times more likely ready for telemedicine system than study participants without private computers. This might be had personal computer helps how technology simplifies our day-to-day operation. 
Health professionals who had good computer skills were 1.9 times more likely to be ready for telemedicine systems than their counterparts. This finding is consistent with a study done in, Mauritius on e-health readiness among health professionals investigated that health professionals who had good computer skills were more likely ready for telemedicine than health professionals who had poor computer skill being computer skills ${ }^{(21)}$.

Correspondingly, the finding also supported by a study conducted in Iran on Telemedicine awareness, attitude, and readiness of health care providers reported that health professionals who had good computer skills were more likely ready than their counterparts for telemedicine systems ${ }^{(23)}$. Furthermore, this finding is in line with another study done in Uganda on health professionals' readiness to telemedicine system stated that those health professionals who had good computer skills were more likely ready than their counterparts ${ }^{(26)}$. This might be being familiar with computer technologies, not such difficult to adapt to new technology.

Study participants who were computer literate were 2.2 times more ready for telemedicine systems than their counterparts. This finding is consistent with a study done in Nigeria on knowledge and perception of e-health and Telemedicine suggested that study participants who were computer literate were more ready for the telemedicine system ${ }^{(27)}$.

In line with another study done on readiness to use telemonitoring in diabetic care among health care providers, which concluded computer literate study participants were more likely ready for the implementation of TM than their relatives ${ }^{(28)}$. The possible explanation might be knowing how to use computer technologies in day-to-day activities increase to use of advanced technologies.

Health professionals who had taken computer training were about 2.1 times more likely ready for telemedicine systems than as compared with those health professionals who had not taken computer training. This is in line with a study done in Libyan ${ }^{(29)}$, postulated health professionals who had taken computer training were more ready for telemedicine system as compared with their counterparts. Similarly, a study conducted on identifying barriers to the development of Telemedicine in developing countries elaborated that health professionals who had taken computer training before were more ready for telemedicine systems ${ }^{(5)}$. Furthermore, another study also supports this study ${ }^{(28)}$.

A possible reason for this could be computer training is more likely to increase participant familiarity in using technologies. Additionally, the explanation might be training and education usually changes people's views, upgrade knowledge levels, and perceptions. Knowing the updated technology passionate for upcoming in their institution.

Health professionals who had internet access at their office were about 2.8 times more ready for the telemedicine system as compared with those health professionals who did not have internet access at the office. This finding is in line with a previous study conducted in Mauritius on health professionals' readiness toward telemedicine system stated that those who had internet access at the office were more 
likely ready to implement Telemedicine than their counterparts ${ }^{(21)}$. Similarly, consistent with the previous study conducted in India on health professionals ready to telemedicine suggested that those health professionals who had internet access at the office were more ready for the telemedicine system than health professionals who did not have internet access ${ }^{(30)}$.

This might be because the internet influences accessing how new advanced technologies applications on the health system. Internet exposure can impact humankind's daily life.

Health professionals who had computer access at their office were about 2.1 times more ready for the telemedicine system as compared with those health professionals who did not have computer access at the office. This finding is in line with a previous study conducted in Lebanon on health professionals' readiness to telemedicine system reported that those study participants who had access to a computer at the office were more likely ready to implement Telemedicine as compared with those study participants with limited computer access ${ }^{(31)}$. Additionally, consistent another study has done concluded that access to a computer at the office has a positive impact on readiness to implement a Telemedicine system(30). Furthermore, another study supports our finding the study done on readiness for delivering digital health reported that access to computers correlated with readiness ${ }^{(32)}$.

The possible reason might be that healthcare providers who have access to computers believe that implementing a Telemedicine system will benefit them personally and that they have the necessary expertise to do it ${ }^{(33)}$.

Study participants who had more than years of work experience were about 3.1 times more ready for the telemedicine system as compared with those study participants who had less than five years of work experience. this finding in line with a study conducted in Lebanon on the readiness of health professionals suggested that study participants with more than five years of work experience were more likely ready than their encounter parts(31). The possible reason might be the more working long years in the health care system might have probabilities of sharing new knowledge with other partners in the workplace. The finding of this study could be generalizable to other private hospitals in Ethiopia.

\section{Conclusion And Recommendation}

In general, the overall readiness of health professionals for the Telemedicine system is moderate. Telemedicine Knowledge, attitude toward Telemedicine systems, own personal computer, computer literacy, computer skill, computer training, internet access at the office, computer access at the office, and work experience were the significant factors for telemedicine readiness. Availing ICT infrastructure and telecommunication infrastructures and provision of training for health professionals are crucial for the adoption of Telemedicine systems. Promotion of Telemedicine systems by the health program managers to the potential users is also important to increase adoption and success rate of Telemedince systems

\section{Abbreviations}


AOR, Adjusted odd ration, EHealth,electronicHealth; TM, Telemedicine; ICT, Information Communication Technology, WHO, World Health Organization, SPSS, statistical package for social sciences

\section{Declarations}

\section{Ethics approval and consent to participate}

Ethical clearance was obtained from the Institutional Review Board (IRB) of the University of Gondar College of medicine and health sciences, institute of public health with reference number (RfNo/IPH/1493/2013). Informed consent was obtained from the study participant after describing the objective of the study, they were also informed about the benefits of the study. All methods performed in this research were done according to relevant guidelines and the Helsinki declaration.

\section{Consent for publication}

Not applicable

\section{Availability of data and materials}

All data generated or analyzed during this study are available from the corresponding author with reasonable request. I can share data used for this study for those need by any means of delivery.

\section{Competing interests}

We authors declare that no competing interests between us

\section{Funding organization}

There is no funding for this study

\section{AuthorContributions}

SMW contribute to the conception of study. SMW, AMN and ATJ contribute to analysis and interpreted the data. SMW prepare and revised the manuscript and agreed to be accountable for all aspects of the work in ensuring that questions related to the accuracy or integrity of any part of the work. SMW, AMN and ATJ contribute to full write up of the manuscript. All authors read and approved the final manuscript.

\section{Acknowledgment}

We would like to thank the University of Gondar institute of public health for the approval of ethical clearance .private hospitals and data collectors and study participants.

\section{References}


1. Kiberu VM, Scott RE, Mars MJBhsr. Assessing core, e-learning, clinical and technology readiness to integrate telemedicine at public health facilities in Uganda: a health facility-based survey. J BMC health services research. 2019;19(1):1-11.

2. Ryu SJHir. Telemedicine: opportunities and developments in member states: report on the second global survey on eHealth 2009 (global observatory for eHealth series, volume 2). \%J Healthcare informatics research2012;18(2):153-5.

3. Cherry JJ, Rich WC, McLennan PLJR, Health R. Telemedicine in remote Australia: The Royal Flying Doctor Service (RFDS) medical chest program as a marker of remote health. \%J RuralRemote Health2018;18(4):[153]-[62].

4. Williams OE, Elghenzai S, Subbe $C$, Wyatt JC, Williams JJFhj. The use of telemedicine to enhance secondary care: some lessons from the front line. \%J Future healthcare journal2017;4(2):109.

5. Bali S. Barriers to development of telemedicine in developing countries. Telehealth: IntechOpen; 2018.

6. Alaboudi A, Atkins A, Sharp B, Balkhair A, Alzahrani M, Sunbul TJJoi, et al. Barriers and challenges in adopting Saudi telemedicine network: The perceptions of decision makers of healthcare facilities in Saudi Arabia. J Journal of infectionpublic health2016;(6):725-33.

7. Sagaro GG, Battineni G, Amenta FJTR. Barriers to sustainable telemedicine implementation in Ethiopia: A systematic review. \%J Telemedicine Reports 2020;1(1):8-15.

8. Hyder MA, Razzak JJJomlr. Telemedicine in the United States: an introduction for students and residents. \%J Journal of medical Internet research. 2020;22(11):e20839.

9. Zanaboni P, Wootton RJBhsr. Adoption of routine telemedicine in Norwegian hospitals: progress over 5 years. \%J BMC health services research2016;16(1):1-13.

10. Kiberu VM, Scott RE, Mars MJHIMJ. Assessment of health provider readiness for telemedicine services in Uganda. \%J Health Information Management Journal2019;48(1):33-41.

11. Beebeejaun MR, Chittoo HJIJSBAR. An assessment of e-health readiness in the public health sector of Mauritius. \%J Int J Sci Basic Appl Res2017;35(1):193-210.

12. Shiferaw F, Zolfo MJGha. The role of information communication technology (ICT) towards universal health coverage: the first steps of a telemedicine project in Ethiopia. \%J Global health action

2012;5(1):15638.

13. Bali S. Enhancing the reach of health care through telemedicine: Status and new possibilities in developing countries. Health care delivery and clinical science: Concepts, methodologies, tools, and applications: IGI Global; 2018. p. 1382-97. 
14. Bali S, Gupta A, Khan A, Pakhare AJJoT, Telecare. Evaluation of telemedicine centres in Madhya Pradesh, Central India. \%J Journal of TelemedicineTelecare 2016;22(3):183-8.

15. Lopez AM, Lam K, Thota RJASoCOEB. Barriers and facilitators to telemedicine: can you hear me now? \%J American Society of Clinical Oncology Educational Book2021;41:25-36.

16. Moffatt JJ, Eley DSJR, health r. Barriers to the up-take of telemedicine in Australia-a view from providers. \%J Ruralremote health2011;11(1):[116]-[21].

17. Saleh S, Khodor R, Alameddine M, Baroud MJBHSR. Readiness of healthcare providers for eHealth: the case from primary healthcare centers in Lebanon. \%J BMC Health Services Research2016;16(1):1-11.

18. Justice EOJIJoE, Technology. E-healthcare/telemedicine readiness assessment of some selected states in Western Nigeria. \%J International Journal of EngineeringTechnology2012;2(2):195-201.

19. Chipps J, Mars MJJoT, Telecare. Readiness of health-care institutions in KwaZulu-Natal to implement telepsychiatry. \%J Journal of TelemedicineTelecare2012;18(3):133-7.

20. Kiberu VM, Scott RE, Mars M. Assessment of health provider readiness for telemedicine services in Uganda. Health Inf Manag. 2019;48(1):33-41.

21. Beebeejaun MR, Chittoo HJIJSBAR. An assessment of e-health readiness in the public health sector of Mauritius. J Int J Sci Basic Appl Res. 2017;35(1):193-210.

22. Kiberu VM, Scott RE, Mars MJBhsr. Assessing core, e-learning, clinical and technology readiness to integrate telemedicine at public health facilities in Uganda: a health facility-based survey. J BMC health services research2019;19(1):1-11.

23. Sheikhtaheri A, Sarbaz M, Kimiafar K, Ghayour M, Rahmani SJECiHAISAPoM. Awareness, Attitude and Readiness of in Mashhad, Iran. J Exploring Complexity in Health: An Interdisciplinary Systems Approach: Proceedings of MIE2016;3(1):142 - 6.

24. Zayapragassarazan Z, Kumar SJJoc, JCDR dr. Awareness, knowledge, attitude and skills of telemedicine among health professional faculty working in teaching hospitals. J Journal of clinicaldiagnostic research: JCDR2016;10(3):JC01.

25. Thapa S, Nielsen JB, Aldahmash AM, Qadri FR, Leppin AJJme. Willingness to Use Digital Health Tools in Patient Care Among Health Care Professionals and Students at a University Hospital in Saudi Arabia: Quantitative Cross-sectional Survey. J JMIR medical education2021;7(1):e18590.

26. Kiberu1 VM, , Richard E Scott P, 2, Maurice Mars M, MD1. Assessment of health provider readiness for telemedicine services in Uganda. Health Information Management Journal. 2019; Vol. 48(1) 33-41. 
27. Abodunrin O, Akande TJIJoHR. Knowledge and perception of e-health and telemedicine among health professionals in LAUTECH teaching hospital, Osogbo, Nigeria. J International Journal of Health Research2009;2(1).

28. Muigg D, Kastner P, Duftschmid G, Modre-Osprian R, Haluza DJBmi. Readiness to use telemonitoring in diabetes care: a cross-sectional study among Austrian practitioners. J BMC medical informaticsdecision making. 2019;19(1):1-10.

29. Ahwidy M, Pemberton L, editors. Assessing Ehealth Readiness Within the Libyan National Health Service by Carrying Out Research Case Studies of Hospitals and Clinics in Both Urban and Rural Areas of Libya. International Conference on Information and Communication Technologies for Ageing Well and eHealth; 2016: Springer.

30. Scott RE, Mars MJSHT, TeleHealth. Telehealth in the developing world: current status and future prospects. Smart Homecare Technology and TeleHealth. 2015;3(2):25-37.

31. Saleh S, Khodor R, Alameddine M, Baroud MJBhsr. Readiness of healthcare providers for eHealth: the case from primary healthcare centers in Lebanon. J BMC health services research. 2016;16(1):1-11.

32. Lennon MR, Bouamrane M-M, Devlin AM, O'connor S, O'donnell C, Chetty U, et al. Readiness for delivering digital health at scale: lessons from a longitudinal qualitative evaluation of a national digital health innovation program in the United Kingdom. J Journal of medical Internet research2017;19(2):e42.

33. Shiferaw F, Zolfo MJGha. The role of information communication technology (ICT) towards universal health coverage: the first steps of a telemedicine project in Ethiopia. Global health action. 2012;5(1):15638.

\section{Tables}

Table 1: socio-demographic characteristic of health professionals working in all private hospitals Amhara Region 2021 $(\mathrm{N}=410)$ 


\begin{tabular}{|llll|}
\hline \multicolumn{1}{|c}{ Variables } & Categories & Frequency $(\mathrm{N})$ & Percentage (\%) \\
\hline Sex & Male & 226 & 55.1 \\
& Female & 184 & 44.9 \\
\hline \multirow{5}{*}{ Professions } & $20-24$ & 29 & 7.1 \\
& $25-29$ & 183 & 44.6 \\
& $30-34$ & 128 & 31.2 \\
& >=35 & 70 & 17.1 \\
& Medical Doctor & 90 & 22.0 \\
& Nurse & 165 & 40.2 \\
& midwifery & 40 & 9.8 \\
& pharmacy & 46 & 11.2 \\
& Medical laboratory & 57 & 13.9 \\
& Other & 12 & 2.9 \\
\hline Work experiences & <2years & 66 & 16.1 \\
& 2-3 years & 58 & 14.1 \\
& 4-5 years & 67 & 16.3 \\
& >5 years & 219 & 53.4 \\
& Diploma & 82 & 20.0 \\
& Degree & 202 & 49.3 \\
& Masters and above & 126 & 30.7 \\
\hline
\end{tabular}

Table 2: Organizational Factors for Health Professionals Readiness towards Telemedicine in Private Hospitals Amhara Region 2021(N=410) 


\begin{tabular}{|llll|}
\hline Variables & Categories & Frequency $(\mathrm{N})$ & Percent(\%) \\
\hline Computer access at the office & Yes & 245 & 59.8 \\
& No & 165 & 40.2 \\
\hline Internet access at the office & Yes & 251 & 61.2 \\
& No & 159 & 38.8 \\
Available IT support & Yes & 252 & 61.5 \\
Computer Training & No & 158 & 38.5 \\
& Yes & 168 & 41.0 \\
Backup power generator & No & 242 & 59.0 \\
& Yes & 334 & 81.5 \\
& No & 76 & 18.5 \\
\hline
\end{tabular}

Table 3:Bivariate and Multivariate Analysis of Factors Associated with Readiness of Health Professionals for Telemedicine System in private Hospitals, Amhara Region, 2021. 


\begin{tabular}{|c|c|c|c|c|c|}
\hline \multirow[t]{2}{*}{ Variables } & \multicolumn{2}{|l|}{ Readiness } & \multirow[t]{2}{*}{$\begin{array}{l}\text { Crude OR }(95 \% \\
\mathrm{Cl})\end{array}$} & \multirow[t]{2}{*}{$\begin{array}{l}\text { Adjusted OR (95\% } \\
\text { Cl) }\end{array}$} & \multirow[t]{2}{*}{$\begin{array}{l}\mathrm{p}- \\
\text { value }\end{array}$} \\
\hline & Ready & Not ready & & & \\
\hline \multicolumn{6}{|l|}{ Knowledge } \\
\hline Good & $221(78.6 \%)$ & $60(21.4 \%)$ & $6.43(4.1,10.2)$ & $2.5(1.4,4.6)^{\star}$ & 0.002 \\
\hline Poor & $47(36.4 \%)$ & $82(63.6 \%)$ & 1.0 & & \\
\hline \multicolumn{6}{|l|}{ Attitude } \\
\hline Favorable & $186(85.7 \%)$ & $31(14.3 \%)$ & $8.1(5.1,13.1)$ & $3 \cdot 2(1 \cdot 6,6 \cdot 2) \star$ & 0.001 \\
\hline Unfavorable & $82(42.5 \%)$ & $111(57.5 \%)$ & 1.0 & & \\
\hline \multicolumn{6}{|l|}{$\begin{array}{l}\text { Personal } \\
\text { computer }\end{array}$} \\
\hline Yes & $223(71.5 \%)$ & $89(28.5 \%)$ & $2.96(1.85,4.71)$ & $3.0(1.5,5.9)^{*}$ & 0.002 \\
\hline No & $45(45.9 \%)$ & $53(54.1 \%)$ & 1.0 & & \\
\hline \multicolumn{6}{|l|}{ Computer skill } \\
\hline Adequate & $188(76.7 \%)$ & $57(23.3 \%)$ & $3.5(2.3,5.4)$ & $1.9(1.1,3.4)^{\star}$ & 0.025 \\
\hline Not adequate & $80(48.5 \%)$ & $85(51.5 \%)$ & 1.0 & & \\
\hline \multicolumn{6}{|l|}{ Computer literacy } \\
\hline Adequate & $186(77.5 \%)$ & $54(22.5 \%)$ & $3.7(2.4,5.7)$ & $2 \cdot 2(1.3,3.9)^{*}$ & 0.007 \\
\hline Not adequate & $82(48.2)$ & $88(51.8 \%)$ & 1.00 & & \\
\hline \multicolumn{6}{|l|}{$\begin{array}{l}\text { Computer } \\
\text { Training }\end{array}$} \\
\hline Yes & 140(83.3\%) & $28(16.7 \%)$ & $4.5(2.8,7.2)$ & $2.1(1.1,4.1)^{\star}$ & 0.022 \\
\hline No & $128(52.9 \%)$ & $114(47.1 \%)$ & 1.0 & & \\
\hline \multicolumn{6}{|l|}{ Work experience } \\
\hline$<2$ years & $35(53 \%)$ & $31(47 \%)$ & 1.0 & & \\
\hline $2-3$ years & $32(55.2 \%)$ & $26(44.8 \%)$ & $1.1(0.5,2.2)$ & $0.9(0.4,2.4)$ & \\
\hline $4-5$ years & $32(47.8 \%)$ & $35(52.2 \%)$ & $0.8(0.4,1.6)$ & $1.1(0.4,2.7)$ & \\
\hline$>5$ years & $169(77.2 \%)$ & $50(22.8 \%)$ & $3.0(1.9,5.3)$ & $3.1(1.4,6.7)^{\star}$ & 0.004 \\
\hline
\end{tabular}




$\begin{array}{llllll}\text { Yes } & 200(79.7 \%) & 51(20.3 \%) & 5.3(3.4,8.2) & 2.8(1.6,5.1)^{\star} & 0.001 \\ \text { No } & 68(42.8 \%) & 91(57.2 \%) & 1.0 & & \end{array}$

Computer access

$\begin{array}{llllll}\text { Yes } & 186(75.9 \%) & 59(24.1 \%) & 3.2(2.1 .4 .9) & 2.1(1.1,3.7)^{\star} & 0.017 \\ \text { No } & 82(49.7 \%) & 83(50.3 \%) & 1.0 & & \end{array}$

Sex

$\begin{array}{llll}\text { Male } \quad 171(75.7 \%) & 55(24.3 \%) & 2.8(1.8,4.2) & 1.5(0.74,2.9)\end{array}$

Female $\quad 97(52.7 \%) \quad 87(47.3 \%) \quad 1.0$

Educational

status

Diploma

Degree

Master and

above

\section{Figures}

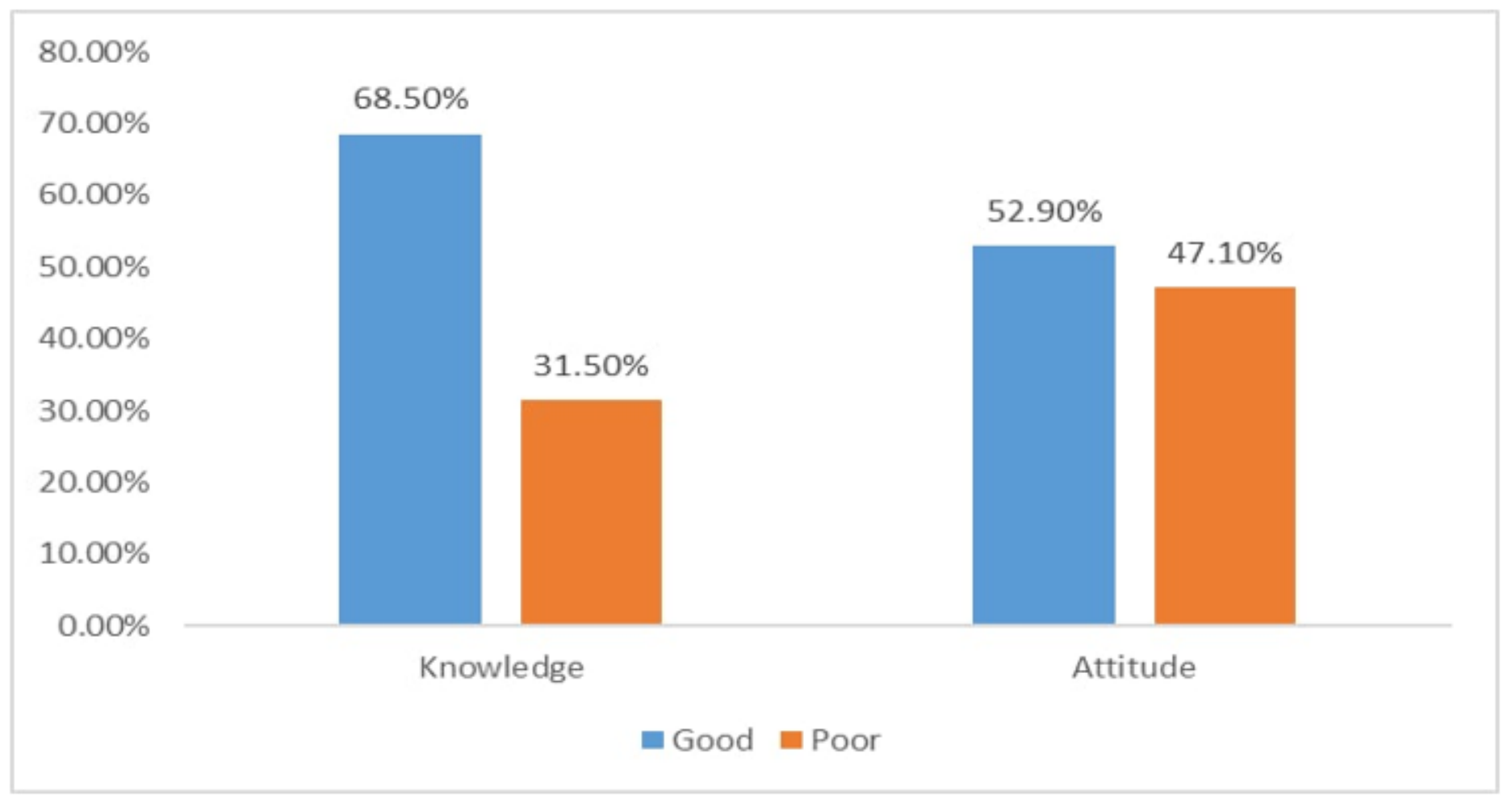

Figure 1 
Knowledge and attitude of health professionals toward Telemedicine at private hospitals in the Amhara Region 2021

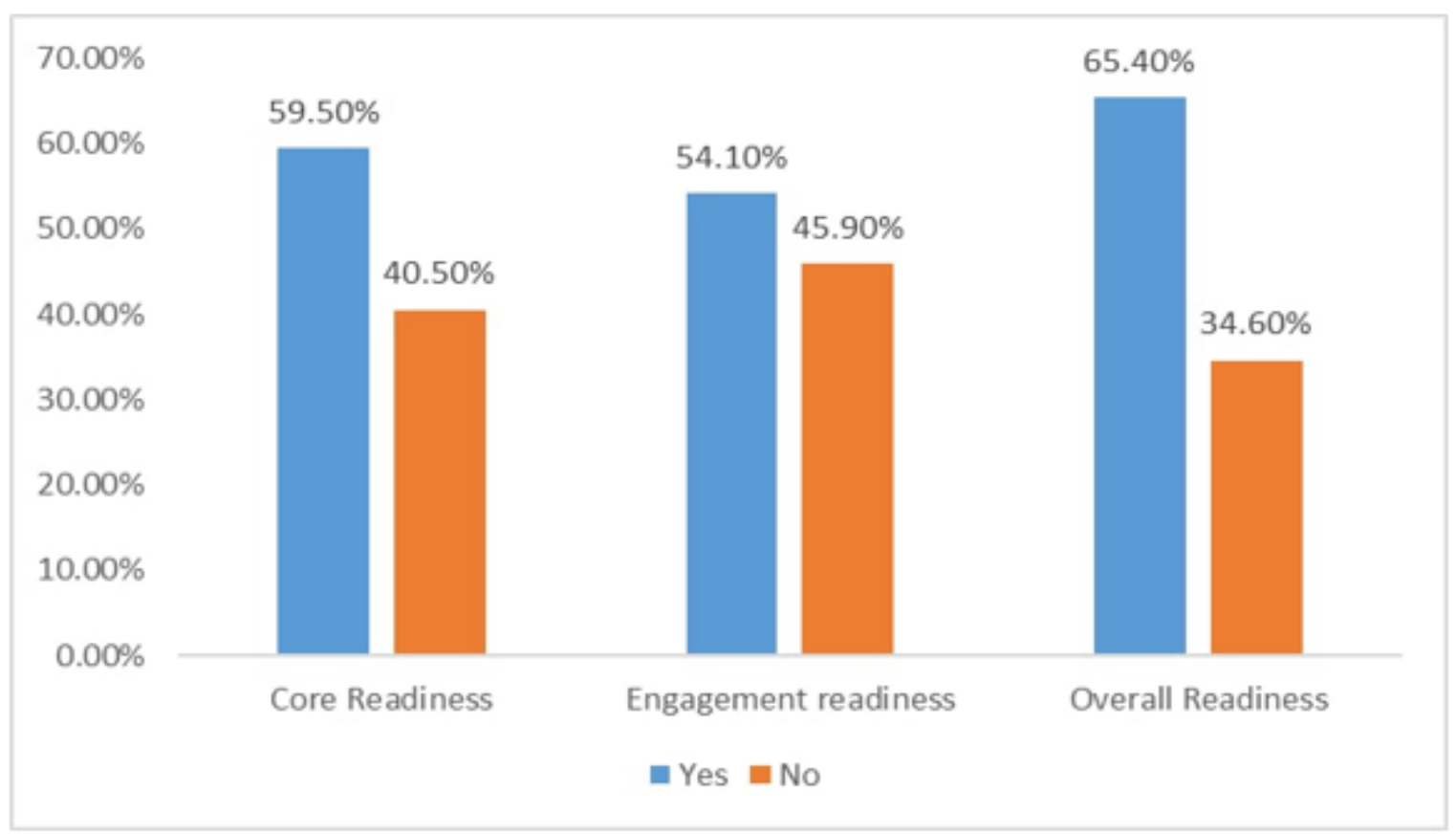

Figure 2

health professionals' readiness towards Telemedicine at private hospitals in Amhara Region 2021 